\title{
ОПЫТ ИСПОЛЬЗОВАНИЯ ЭМПИРИЧЕСКИХ МЕТОДОВ В КУЛЬТУРФИЛОСОФСКИХ ИССЛЕДОВАНИЯХ
}

\section{THE EXPERIENCE OF USING EMPIRICAL METHODS IN CULTURAL AND PHILOSOPHICAL RESEARCH}

\section{E. Soboleva}

Summary: The article considers an example of using the interviewing method in cultural and philosophical studies. We are talking about the analysis of in-depth interviews of composers of the Lower Volga region in order to identify such issues as the new conditions for the existence of musical organizations, the state of modern music, the content and semantic basis of musical works, genre priorities, and the philosophy of creativity. In this context, the object of the study is musical culture, and the subject is the active position of regional composers in relation to the processes that are taking place in the musical world today and are reflected in their works. Using this method allows you to highlight the identified problems «from the inside», which can contribute to a deeper understanding of them.

Keywords: interview, music culture, composer, creativity, philosophy of creativity, Union of Composers.

\author{
Соболева Елена Анатольевна \\ К.ф.н., дочент, ФГБОУВО «Астраханская \\ государственная консерватория». \\ elenso10@mail.ru
}

Аннотация: В статье рассматривается пример использования метода интервьюирования в культурфилософских исследованиях. Речь идет об анализе глубинного интервью композиторов Нижнего Поволжья с целью выявления таких вопросов как, новые условия существования музыкальных организаций, состояние современной музыки, содержательно-смысловая основа музыкальных произведений, жанровые приоритеты, философия творчества. В данном ключе объектом исследования выступает музыкальная культура, а предметом - деятельностная позиция региональных композиторов в отношении тех процессов, которые сегодня происходят в музыкальном мире и отражаются в их произведениях. Использование данного метода позволяет осветить обозначенные проблемы «изнутри», что может способствовать более глубокому их осмыслению.

Ключевые слова: интервью, музыкальная культура, композитор, творчество, философия творчества, Союз композиторов.
$\mathrm{O}$ дним из методов современного эмпирического исследования является интервьюирование, что предполагает обработку и анализ данных, полученных в ходе устного общения (беседы). В рамках культурфилософии подобный метод используется нечасто, однако он имеет свои преимущества в рассмотрении интересующей проблемы как бы «от первого лица». В настоящей статье предлагается анализ результатов опроса глубинного интервью, целью которого явилось исследование деятельности региональных композиторов, точнее, их позиции в отношении тех процессов, которые сегодня происходят в музыкальном мире и отражаются в их произведениях. Современная музыкальная отечественная культура испытывает не только внутренний кризис, связанный с уровнем потребляемого музыкального материала, но и с обесцениванием статуса профессии музыканта, если речь не идёт о выдающихся музыкантах с мировым именем. С момента открытия первой Петербургской консерватории в России (1862) на сегодняшний день в РФ действуют 11 консерваторий и около 32-х учебных заведений, где готовят профессиональных музыкантов, среди которых выпускаются и композиторы. Они-то и пополняют составы столичных и региональных музыкальных организаций, однако, если учесть, что в нашей стране действуют 48 музыкальных союзов, в основном региональных, насчи- тывающих более 1000 членов, можно себе представить, какое количество музыкального материала так и не обретёт своего слушателя. В этой связи, исследование позиции современных профессиональных композиторов, проживающих в регионах России, в отношении дальнейшей судьбы отечественной и мировой музыкальной культуры, а также содержательный аспект их творчества представляется интересным, так как деятельность композиторов (как профессионалов, принадлежащих мировому сообществу деятелей искусства) в какой-то степени «тормозит» окончательный переход музыки в цифровую среду, где сочинение и исполнение станут прерогативой компьютерных и мобильных программ. В данной статье будет представлен материал исследования глубинного интервью с композиторами Нижнего Поволжья И. Дородновым [3], А. Павлючуком [7], С. Полозовым [8], Ю. Гонцовым [6], А. Манджиевым [4], П. Морозовым [5], А. Рындиным [1], Л. Бутаковым [2] и др. Опрос производился октябре - ноябре 2020 г.

В современных условиях для композиторов всё чаще встаёт проблема невостребованности, работы «в стол», вынужденности писать в малых формах и жанрах. Особенно остро такую диспропорцию ситуации переживают композиторы «первого поколения», расцвет творчества которых пришёлся на советский период, привыкших 
к «твердому плечу» центральной организации (Союзу композиторов РСФСР). Однако композиторы «второго поколения», чьё формирование происходило после социальных пертурбаций 90-х годов, более оптимистично оценивают свою роль и положение в поле современного музыкального пространства.

Основными вопросами проведённых интервью стали: новые условия существования музыкальных организаций, состояние современной музыки, содержательно-смысловая основа музыкальных произведений, жанровые приоритеты, философия творчества.

Приведём некоторые данные общего анализа глубинного интервью.

После 2000-х годов изменилось финансовое и политическое положение Союза композиторов РСФСР (СК Р(ФСР), регионы лишились мощной финансовой поддержки центра, а региональные композиторы - возможности финансирования издания нот, выступления на столичных теле и радиоканалах, исполнения своих сочинений на площадках столиц, командировок в Дома творчества. Особенно остро это коснулось композиторов «первого поколения», расцвет творчества которых пришёлся на годы советского периода. Композиторы «второго поколения», несмотря на то, что их детство прошло в СССР, не испытали на себе последствий культурной «ломки», так как формировались в музыкальной академической среде - особой, достаточно консервативной сфере человеческой коммуникации. Что касается утраченной поддержки со стороны музыкальной организации (речь идёт о бывшей СК РСФСР, ныне - СК России), которая являлась «альма-матер» для старших коллег по цеху, то здесь даётся противоречивая оценка идее культивирования композиторского поприща, прежде всего в регионах. С одной стороны, наличие свыше шестисот композиторов в стране - прекрасный показатель, указывающий на высокий уровень музыкальной культуры, так как ремесло композитора подразумевает не только соответствующее музыкальное образование, но и талант, без которого немыслимо композиторское творчество. С другой стороны, такое обилие композиторов порождает их невостребованность, малоизвестность, превращает их деятельность в творчество для самих себя. То есть возникает извечная проблема отношений между массовым и элитарным искусством в том смысле, что процент людей, настроенных слушать классическую музыку, попрежнему очень мал (даже в советское время, при пропаганде классического наследия со стороны государства, процент потребления классики вряд ли выходил за рамки 30\%). Это может быть связано с тем, что элитарное искусство нажимает на болевые, экзистенциальные точки, которые человек не всегда готов обнажать. Поэтому для современного художника проблема популярности, как фактора первого места в массовом слушательском рейтинге, не стоит особо остро, так как у любого мастера есть свой зритель и слушатель. Другое дело, что композитор, в отличие от того же художника или писателя, общается со слушателем опосредовано - через исполнителя, что создаёт определённую проблему исполнения написанных сочинений. Поэтому можно сказать, что у каждого композитора есть и свой исполнитель, на которого часто ориентировано сочинение, и от которого в какой-то степени зависит судьба произведения. Являясь проводником композитора вовне, исполнитель превращается в первого и главного ценителя, так как именно он обеспечивает более широкие связи композитора с окружающим миром. Нельзя сказать, что такая особенность взаимодействия композитора и исполнителя не была характерна для прошлого времени. Чисто теоретически, у современного композитора больше возможностей не замыкаться в обособленном пространстве своего региона. При помощи современных средств коммуникации он имеет все условия для выхода на международный уровень. Но это теоретически, а фактически, без определённой поддержки и наработанных связей - это трудновыполнимая задача. В советскую эпоху именно СК РСФСР предоставлял такие возможности своим членам, так как брал на себя издание нот, эфиры на радио, телевидении, финансировал участие в фестивалях не только в центре, но и за рубежом. Это давало возможность композиторам активно участвовать в музыкальной жизни своей страны и мира, делиться музыкальными идеями и получать достойную критику в центральных и региональных музыкальных изданиях. В сегодняшних реалиях каждый может самостоятельно планировать свою творческую деятельность, без спущенных сверху обязательств писать оперу, балет, симфонию и т.д. Пребывая в состоянии свободного выбора, композитор также вовлекается в процесс свободной конкуренции, причём не только с собратьями по цеху, но и с музыкальными электронными технологиями, которые набирают всё большую популярность. Однако этот фактор не рассматривается пессимистично представителями как первого, так и второго поколения, так как практически все опрошенные считают, что реальности и животворности музыкальной мысли трудно противопоставить электронный вариант - он безнадёжно проиграет.

Один из главных вопросов, поднятых в интервью состояние современной музыки, которая, начиная с XX века, была направлена на поиск новых форм музыкального выражения, от нотописи до звуковой палитры. Как отметил астраханский композитор Л. Бутаков, в искусстве всегда существует поиск новых форм, что отражается в истории искусства, но при этом нельзя исключать возвращение к прежним идеям и формам. Начиная с XVIII века, в музыкальном мире каждого столетия наблюдается устойчивая тенденция: примерно в первой половине века - происходит стремление к «пентатонике» (строгости формы и стиля), во второй - к «хроматике» 
(тяготение к свободной форме и полистилистике). В XX веке это просматривается в творчестве С. Прокофьева, Д. Шостаковича («пентатоника») и П. Булеза, К. Штокхаузена, К. Пендерецкого («хроматика»). Более того, данный переход систем друг в друга часто можно наблюдать в индивидуальном творчестве многих композиторов. В качестве примера можно привести А. Шёнберга, творившего на стыке XIX и XX веков, и В. Сильвестрова, творчество которого пришлось на XX и XXI века. В их музыке данный «слом» (смена парадигмы) прослеживается с заметной очевидностью. Есть, конечно, «исключения»- Г. Свиридов, А. Гаврилин (их творчество пришлось на вторую половину XX века), но при этом они остались в контексте «пентатоники». Однако переход от «пентатоники» к «хроматике» не означает движения от простого к сложному и обратно (в искусстве нет прогресса). Каждый новый переход к «хроматике», в каком-то смысле, путь обновления «пентатоники», обусловливающий связность всей конструкции. В философском смысле - это процесс осмысления человеком самого себя, собственной «самости», который не мыслим без определённых периодов. Более того, концепт «пентатоника/хроматика» существует ещё как некая эпохальная характеристика, определяющая специфику не полувека, а века - это метапарадигма, представляющая собой общее движение и развитие музыкального искусства. XVIII век, как ни странно, век «хроматики» (вспомним музыку И. С. Баха, мало исполняемую в XIX веке, а в XX обретшую удивительную популярность у исполнителей), XIX век - соответственно эпоха «пентатоники», а вот XX - вновь «хроматики». Исходя из этого, логично предположить, что XXI век должен стать веком «пентатоники», и эти процессы уже наблюдаются в музыкальном мире. В пример можно привести творчество Р. Щедрина, С. Губайдулиной, В. Сильвестрова, даже авангардиста В. Тарнопольского. Те же процессы можно наблюдать и в литературе. Современные писатели всё меньше создают сложные конструкции, требующие необычайного напряжения от читателя, превращающие литературу в некую борьбу с материалом. Можно сказать, что особенно в отечественной литературе происходит процесс перехода от «дионисийского» к «аполлоническому», говоря языком Ницше. Если рассуждать более глобально, то и культуры в целом можно охарактеризовать по вышеозначенному принципу: русская культура тяготеет к «пентатонике», западная - к «хроматике».

Ещё одна проблема, встроенная в глубинное интервью - усложнение музыкального языка и его нотация. B XX веке происходит кардинальный переворот в художественных системах. В музыке появляется новое направление, получившее название «современная музыка», совершившее ломку прежних стереотипов музыкального мышления и потребовавшее перестройку не только академической системы преподавания композиции, но и исполнительских приёмов. Однако российская исполнительская школа до сих пор более сориентирована на классическое наследие, и «новый» музыкальный язык продолжает оставаться сложным не только для слушателей, но и для исполнителей. В условиях усиливающегося выбора публика в пользу примитивности музыкального языка, происходит ещё большее её обособление от той альтернативы, которую предлагают современные композиторы, создающие сложные музыкальные конструкции. Сюда же можно отнести проблему современной системы фиксирования музыкальных произведений, где задачей первого плана определяется создание как можно более адекватной нотации для исполнителя, который вынужден подчас «догадываться», что же предлагает ему сыграть композитор. Данная ситуация чревата появлением более громоздкой системы, требующей дополнительных усилий, а может и введения специальных дисциплин в консерваториях и музыкальных колледжах.

Одним их самых важных вопросов в деятельности композитора является вопрос о творческом процессе от идеи произведения, её философского наполнения до исполнения, то есть непосредственного рождения музыки. Несмотря, как говорилось выше, на разительные изменения вкусовых предпочтений публики, делающей выбор в пользу «лёгких» по содержанию и смыслу произведений, композиторы, как первого, так и второго поколения продолжают писать музыку, содержательно уводящую в философские проблемы человека - от темы одиночества до поиска смысла жизни. Это проявляется в программности музыкальных сочинений, в жанровых предпочтениях - от камерных пьес до музыкальных спектаклей (опер, балетов, мюзиклов). Однако всё большим приоритетом у современных композиторов пользуются жанры камерной музыки, хотя многие выдающиеся исполнители XX века (С. Рихтер, Н. Гутман, Э. Версаладзе, М. Юдина) полагали, что самые яркие и интересные сочинения относятся именно к камерной музыке. В современных реалиях за этим стоит не только определённый художественный замысел, но и чисто утилитарный интерес - камерные произведения не требуют максимальных ресурсов, как материальных, так и человеческих, для исполнения произведений.

Итак, исходя из частично представленного материала, можно сделать вывод, что современные композиторы весьма критически относятся к недавнему историческому прошлому, не считают своё поколение «ущемлённым», достаточно трезво оценивают свои силы и возможности в пространстве современного мира. Такое мировоззрение можно назвать позитивным, в нём нет апокалиптических нот, так как историю музыкальной культуры они воспринимают не линейно. С другой стороны, композиторы продолжают академическую, присущую русской композиторской школе, традицию, где акцентируется философичность творчества, идея служения искусству, приоритет высокого над профанным, тем самым создавая противовес потоку массовой музы- 
ке сомнительного уровня. Хотя в сегодняшних реалиях композитор перестал быть героем своего региона, его творчество востребовано только в узко-специфической среде и непосредственно в профессиональной деятельности. В городах Нижнего Поволжья (Саратове, Астрахани) в течение последних 20 лет не было ни одной крупной премьеры оперы или балета местных композиторов (хотя крупные формы ими создаются). Более того, городские театры (музыкальные и драматические) в большинстве случаев не сотрудничают с местными композиторами, отдавая приоритеты классическому (проверенному временем) репертуару, либо заключая контракты с современными московскими или петербургскими авторами. Также местные масс-медиа не проявляют особого интереса к творчеству «своих» композиторов. Может ли подобная ситуация постепенно свести на нет деятельность не только музыкальных организаций в регионах, но и саму профессию композитора? Во всяком случае, деятельность, образовавшейся в 2009 г. дочерней СК России музыкальной организации МолОт под руководством Я. Судзиловского, направленная на консолидацию молодых композиторов (третьего поколения), вселяет надежду, что музыкальные организации регионов продолжат своё существование, а общая позиция опрошенных композиторов, которая определилась по итогам интервью, позволяет с оптимизмом смотреть в будущее и верить, как было сказано выше, что общество всегда будет нуждаться в животворности музыкальной мысли.

\section{ЛИТЕРАТУРА}

1. Александр Владимирович Рындин / Астраханская государственная консерватория. URL: https://astracons.ru/?page_id=16738 (Дата 0бращения 4.04.2021).

2. Бутаков Леонид Викторович / Музыковеды Астраханской консерватории. URL: https://mvastracons.ru/?p=41949 (Дата 0бращения 4.04.2021).

3. Дороднов Игорь Николаевич / Союз композиторов России. URL: https://www.unioncomposers.ru/page/search/?query=дороднов (Дата обращения 1.04.2021).

4. Манджиев Аркадий Наминович / Союз композиторов России. URL: https://www.unioncomposers.ru/composer/view/?id=41 (Дата 0бращения 1.04.2021).

5. Морозов Павел Павлович / Союз композиторов России. URL: https://www.unioncomposers.ru/composer/view/?id=83 (Дата 0бращения 1.04.2021).

6. Музыка опять возвращается (Интервью с астраханским композитором Ю.П. Гонцовым) // PHILHARMONICA. International Music Journal. - 2019. - № 6. C. 8-16. D0I: 10.7256/2453-613X.2019.6.31113 URL: https://nbpublish.com/library_read_article.php?id=31113

7. Павлючук Алексей Вячеславович https://www.unioncomposers.ru/composer/view/?id=662 (Дата обращения 1.04.2021).

8. Полозов Сергей Павлович / Союз композиторов России. URL: https://www.unioncomposers.ru/composer/view/?id=180 (Дата 0бращения 1.04.2021). 